\title{
CUSCO Y LA GLOBALIZACIÓN
}

Ligia Isabel Somocurcio Alarcón ${ }^{1}$

\section{RESUMEN}

La globalización es la característica principal del actual ciclo histórico que atraviesa el mundo. Hoy en día, todos los Estados participan de la dinámica de la globalización. Las distintas economías nacionales se integran en una única economía de mercado mundial; proceso acelerado por el impacto de las tecnologías de la información y comunicación. La globalización en el ámbito cultural y social convierte al mundo en una red de relaciones sociales por donde circulan de manera fluida símbolos, imágenes, bienes y personas, que en su mayoría han sido generados en otros territorios. En el Perú, Lima y las capitales regionales como el Cusco, son atractivas para inversiones ligadas al sector servicios (turismo) y al sector industrial. En estas ciudades surgen múltiples centros especializados, comerciales, culturales y otras, que generan alta densiad de actividades y flujos de capital e información. En esta perspectiva, no se trata de buscar cómo adaptarse a la globalización, sino se trata de ver cómo construir alternativas de alcance local, regional, nacional y mundial, para nuestro desarrollo.

PALABRAS CLAVES: Globalización, Economía, Sociedad, Cultura, Desarrollo

\begin{abstract}
The world's current historical cycle has the globalization as main feature. Today, all states are part of the globalization dynamics. The various national economies are integrated into one single global market economy; this process is accelerated by the information technology
\end{abstract}

1 Máster en Economía con mención en Globalización: Procesos Sociales y Políticas Económicas. Docente Principal de la Facacet. Universidad Nacional de San Antonio Abad del Cusco.E-mail: ligia.somocurcio@gmail.com 
and communication impact. Globalization in cultural and social spheres turns the world into a social relations network in which symbols, images, goods and people fluidly circulate, most of whom have been generated in other territories. In Peru, Lima and regional capitals such as Cusco, are attractive for investments linked to the service sector (tourism) and the industrial sector. In these cities many specialized centers, commercial, cultural networks arise generating activities, capital flows and information in high density. In this perspective, it is not about seeking how to adapt to globalization, but see how to build alternatives for our development at local, regional, national and global levels.

KEYWORDS: Globalization, economy, society, Culture, development.

-1 presente trabajo es parte de la Eponencia presentada en el "II Coloquio: Cusqueñidad, Peruanidad y

“Cuanto más se globalizan los lugares estos se tornan más singulares y específicos, es decir, más únicos. Un claro ejemplo de ello es el Cusco y Machu Picchu, que hoy brillan en el mundo con más singularidad, resaltando esa característica de ser Únicos."

Cultura Andina"2, organizado por la Empresa Municipal de Festejos del Cusco y el Instituto Americano de Arte-Cusco.

En este marco, no podía faltar el tema vinculado a la "globalización" como tema central, por cuanto va construyendo el escenario, donde cualquier acción a realizar en la búsqueda de la construcción de nuestro destino histórico, no tendría futuro, si no la consideramos adecuadamente, en las múltiples dimensiones que presenta.

\section{CUSCO Y LA GLOBALIZACIÓN}

El Cusco como región, está indisolublemente ligado al destino de la capital histórica del Perú, cuna del Tahuantinsuyo: la ciudad del Cusco. Tal como ocurre con otras grandes ciudades históricas de nuestro planeta; Jerusalén, Bagdad, Pekín, Roma, Atenas, Constantinopla, Londres, París o México. El Cusco presenta esta maravillosa simbiosis, donde el pasado, presente y futuro, confluyen para enmarcar los hitos trascendentes, hechos y situaciones de la interacción entre el espacio geográfico y su población.

Recordemos que el 8 de enero de 1944, por iniciativa del ilustre cusqueño Humberto Vidal Unda, el Instituto Americano de Arte y un grupo de distinguidas personalidades acordaron rendir homenaje al Cusco, para "dialogar sobre las cosas que al Cusco le faltan y sobre lo que se debe hacer".

Como años antes el amauta José Carlos Mariátegui, había empezado una cruzada para peruanizar al Perú, el Dr. Vidal emprendió la suya, cusqueñizar a los cusqueños, para rescatar en el orden emocional, el valor del pasado cusqueño en la historia americana, buscando el autodescubrimiento y autovaloración de aquella generación de hombres que realizarían "una verdadera revaloración espiritual" acaso el movimiento espiritual y humano más importante del siglo y la realización cultural mestiza de mayor envergadura hecha en esta ciudad (Gutiérrez Samanez, 2008)

Propuesta que por su importancia, hoy debe convertirse en un gran faro, para todos aquellos que anhelamos mejores destinos, para el Cusco y el Perú. Si queremos honrar al Cusco, pasemos de las ideas a la acción; para impulsar su crecimiento y desarrollo regional, tal cual

2 El "II Coloquio: Cusqueñismo, Peruanidad y Cultura Andina", se desarrolló en el "mes jubilar de la ciudad del Cusco", el 2 de junio de 2014, en el Salón Consistorial de la Honorable Municipalidad del Cusco, con el propósito de reafirmar los valores y la identidad de nuestra cultura local, regional y nacional. 
una locomotora, pues la ciudad del Cusco es su corazón.

Siete décadas después de esta gran iniciativa (dada por Humberto Vidal y patrocinada por el Instituto Americano de Arte), debemos enfrentar el hecho de que la ciudad y la Región del Cusco, han quedado postergados en su presencia y proyección histórica frente a otras ciudades del Perú: Arequipa en el sur y Trujillo en el norte del país. Los cusqueños, vivimos en la añoranza de un pasado glorioso, en medio de un vasto campo mundial llamado globalización.

La globalización, es la característica principal del actual ciclo histórico inaugurado por la caída del muro de Berlín, en noviembre de 1989, y la desaparición de la Unión Soviética, en diciembre de 1991. Hoy en día, todos los países están dentro de esta dinámica, acelerada por el impacto de la tecnología de la información y comunicación; la cual ha generado tensiones y creciente incertidumbre en el escenario económico mundial.

"En su sentido amplio, globalización se refiere al conjunto, cada vez más amplio, de relaciones interdependientes entre gente de diferentes partes de un planeta que, por casualidad, está dividido en naciones" (Daniels, Radebaugh, \& Sullivan, 2012).

La globalización puede entenderse como el proceso de acelerada interacción entre las economías de los países en el mundo; a través de la producción, el comercio, los flujos financieros, la difusión tecnológica, las redes de información y las corrientes culturales. Es una fase reciente del proceso secular de internacionalización económica, iniciada en las últimas décadas del siglo veinte, con grandes cambios planetarios a nivel monetario, cambiario, energético, comercial y tecnológico. Consiste en la creciente integración de las distintas economías nacionales en una única economía de mercado mundial. Este proceso depende del crecimiento económico, el avance tecnológico y la conectividad humana es decir el transporte y las telecomunicaciones.

Su empuje y su potencia son tales, que nos obligan a redefinir conceptos fundamentales sobre los que reposaba el edificio político y democrático levantado a finales del siglo dieciocho: conceptos como Estado-Nación, soberanía, independencia, fronteras, territorio, democracia, Estado benefactor, ciudadanía, entre otros. La globalización traduce sobre todo el creciente poder de los mercados financieros, el retroceso de los Estados nacionales y las dificultades para establecer poderes supranacionales capaces de orientarla hacia el interés general.

La globalización de la economía y de la sociedad engendra la mundialización del espacio geográfico, aportándole un nuevo significado. El espacio adquiere hoy una importancia fundamental, pues la naturaleza se transforma en su totalidad, en fuerza productiva. Si los lugares han sido alcanzados de modo directo o indirecto por las necesidades del proceso productivo, se crean paralelamente selectividades y jerarquías de utilización debido a la competencia activa o pasiva entre los diversos agentes, es decir surgen nuevas realidades, importantes en potencia y en los hechos.

Cuanto más se globalizan los lugares estos se tornan más singulares y específicos, es decir, más únicos. Un claro ejemplo de ello es el Cusco y Machu Picchu, que hoy brillan en el mundo con más singularidad, resaltando esa característica de ser Únicos.

Parto de la premisa de que si bien todos sabemos que el Cusco (como todo el mundo lo está) ya está inmerso en el actual proceso de globalización, sin embargo, pareciera ser que no todos lo sienten y perciben así, de suerte que el actuar de la ciudadanía difiere ante el conocimiento que de este fenómeno se tiene. Vamos por otra senda y no por la apropiada para aprovechar las cosas buenas que la globalización implica y 
resguardarnos de las cosas negativas que ella nos trae.

En este contexto, si bien la actual globalización abre numerosas oport unidades en la articulación e integración mundiales, con todo lo que ello implica; también representa serias amenazas en las regiones y países que se mantienen al margen del ritmo de los tiempos que le son propios. Agudiza los mecanismos de dominio, explotación y dependencia $\mathrm{y} / \mathrm{o}$ profundiza las brechas $\mathrm{y}$ asimetrías existentes. Razón por la cual la globalización genera en su propia matriz, como respuesta automática el despertar de

\section{"Como se puede observar,} con la globalización se han producido cambios sustanciales en la estructura de la actividad económica, con serias repercusiones en la organización del territorio."

los regionalismos y la búsqueda de la propia identidad. Produciendo formidables retos, muchos de ellos paradójicos, tales como el resurgimiento del "proteccionismo" en algunos países.

La globalización en el ámbito cultural y social está convirtiendo al mundo entero en una red de relaciones sociales por donde circulan de manera fluida símbolos, imágenes, bienes y personas. En la actualidad la mayor parte de los bienes y mensajes que se reciben en cada localidad no han sido producidos dentro del mismo territorio. No surgen de relaciones peculiares de producción, ni llevan en ellos los signos exclusivos que los vinculen a la comunidad nacional, sino otras señales que más bien indican su pertenencia a sistemas transnacionales sin territorio, donde para los sujetos el proceso de construcción de identidades se encuentra en permanente negociación entre lo local y lo global, lo nuestro y lo ajeno, recreándose en medio de la creciente interacción entre diversas culturas sin tener muchas veces un anclaje claro en un territorio determinado.

"De 1962 a 1990, el Perú vivió tres décadas perdidas, cada cual más perdida que la anterior. Involucrados ideológicamente con la combinación inflamable de la teoría de la dependencia y de la reivindicación indigenista, matizada con la creciente hegemonía intelectual que el socialismo peruano desplegaba desde inicios del siglo veinte..." (D'Medina Lora, 2012).

En la década de 1990, con las políticas de ajuste emprendidas por el gobierno de Fujimori, en base al "Consenso de Washington"3, la apertura al exterior y la reinserción del Perú en el mundo, llevaron a una mayor liberalización de la economía peruana. Proceso que a la fecha continúa, con la firma de acuerdos y tratados comerciales con los diferentes países del mundo. Tenemos relaciones con más de un centenar de países; y hemos sido sede de cumbres de alcance mundial.

3 Documento, escrito por John Williamson en 1990, consta de diez medidas para una sana política económica: $1^{\circ}$ Disciplina en la política fiscal, enfocándose en evitar grandes déficits fiscales en relación con el Producto Interno Bruto. $2^{\circ}$ Redirección del gasto público en subsidios ("especialmente de subsidios indiscriminados") hacia una mayor inversión en los puntos claves para el desarrollo. $3^{\circ}$ Reforma tributaria, ampliando la base tributaria y adopción de tipos impositivos marginales moderados. $4^{\circ}$ Liberalización de las tasas de interés: que sean determinadas por el mercado y positivas (pero moderadas) en términos reales. $5^{\circ}$ Tipo de cambio competitivo. $6^{\circ}$ Liberación del comercio: liberación de las importaciones, con un particular énfasis en la eliminación de las restricciones cuantitativas (licencias, etc.); cualquier protección comercial deberá tener aranceles bajos y relativamente uniformes. $7^{\circ}$ Liberalización de las barreras a la inversión extranjera directa. $8^{\circ}$ Privatización de las empresas estatales. $9^{\circ}$ Desregulación: abolición de regulaciones que impidan acceso al mercado o restrinjan la competencia. $10^{\circ}$ Seguridad jurídica de los derechos de propiedad. 
En este contexto, las regiones y ciudades experimentan la globalización de diferente manera. Las regiones que crecen (no necesariamente se desarrollan), son las que han podido insertarse bien en la economía mundial a través de sus recursos naturales renovables o no renovables, de procesos exportadores asociados a la industria manufacturera liviana a través de centros metropolitanos articulados a la economía mundial por servicios financieros, comerciales y turísticos.

Son las regiones que trascienden las simples ventajas absolutas y relativas (comparativas) para transformarlas en ventajas competitivas, que incorporan mayor valor agregado y constituyen eslabones sólidos dentro de la cadena de valor de sus productos.

Gracias a las exportaciones, impulsadas por la demanda mundial y las relaciones comerciales con el extranjero, Cusco como ciudad y Región, así como el Perú han mejorado sus indicadores macroeconómicos, empezando a destacar por su dinamismo económico.

En el 2015 (...)Cusco aportó el 4,8 por ciento al Valor Agregado Bruto (VAB) nacional, ocupando el tercer lugar a nivel departamental. Asimismo, Cusco registró un crecimiento promedio anual de 8,5 por ciento durante el periodo 2008-2015. La principal actividad económica fue la extracción de gas y minerales, que representó el 48,4 por ciento del VAB del departamento, seguida por construcción ( 7,7 por ciento), comercio (7,4 por ciento), manufactura (4,9 por ciento), agricultura, ganadería, caza y silvicultura $(4,7$ por ciento), y las demás actividades económicas (26,9 por ciento) (BCRP, 2016, pág. 3).

\section{EN CUANTO AL TURISMO}

El año 2015, el número de arribos a los establecimientos de hospedaje ascendió a 2881628 personas, mostrando una tasa de crecimiento promedio anual de $10,1 \%$ durante el periodo 2006-2015 (...) el número de llegadas de visitantes al santuario histórico de Machu Picchu creció a un ritmo anual de $6,6 \%$, registrándose 1 282515 visitantes en el año 2015 (BCRP, 2016, pág. 6)

El indicador que se emplea a nivel nacional para medir la evolución de la economía es el índice de Competitividad Regional, cuya estimación la realiza el Consejo Nacional de Competitividad, según el cual el departamento de Cusco se encuentra en el puesto doce a nivel nacional, con un índice de competitividad de 0,45 para el período 2013-2014, encontrándose en el estadio intermedio (Gobierno Regional del Cusco - CEPLAN, 2016, pág. 74).

Como se puede observar, con la globalización se han producido cambios sustanciales en la estructura de la actividad económica, con serias repercusiones en la organización del territorio. Estas transformaciones son observadas a través de los cambios en los sectores de la actividad económica y en las transformaciones espaciales (urbano regionales y también rurales).

En la actualidad, la combinación de la crisis mundial (persistente recesión en las economías más desarrolladas) y el retorno al proteccionismo, lleva a una situación muy delicada a las economías regionales, poniendo en cuestión su patrón de inserción internacional, como consecuencia de los persistentes desequilibrios comerciales, financieros $\mathrm{y}$ regulatorios que afectan fuertemente a los países desarrollados y a las economías de los países con quienes mantienen relaciones económicas y comerciales.

Lo que ocurre a nivel mundial, también se refleja al interior del país y de la región: en cada espacio regional existe una ciudad rectora. En el Perú, el proceso de globalización incorpora a Lima Metropolitana y las metrópolis regionales como el Cusco, que son atractivas para inversiones ligadas al sector servicios (turismo) o al sector minero. En estas 
ciudades surgen múltiples centros especializados y redes de actividades informacionales, industriales, comerciales y culturales, que generan alta densidad de actividades y flujos de capital e información. Presentándose también paradojas, como que en la región del Cusco, no se ha dado una efectiva articulación entre la base productiva agropecuaria y la dinámica turística que se vive, las cuales están desvinculadas de otro sector productivo importante como es la minería.

La ciudad del Cusco es reconocida mundialmente como patrimonio histórico

\section{"La ciudad del Cusco es} reconocida mundialmente como patrimonio histórico y cultural de la humanidad al poseer restos arqueológicos y culturales, gran diversidad de flora, fauna y climas naturales que le dan un gran potencial de desarrollo turístico."

y cultural de la humanidad al poseer restos arqueológicos y culturales, gran diversidad de flora, fauna y climas naturales que le dan un gran potencial de desarrollo turístico, además exhibe una variedad importante de productos para exportación en la minería, hidrocarburos, agricultura y manufactura, especialmente por el gas, cobre, café sin descafeinar ni tostar, maíz, achiote y otros productos andinos. Gracias a estos elementos se tiene un desarrollo regional que involucra actividades tan diversas como la artesanía, construcción, servicios y alimentos, entre otros. Con esta premisa, se hace imperativo incorporar mayor valor agregado y desarrollar cadenas productivas con eslabonamientos hacia adelante y hacia atrás. Sin olvidar que en la Región Cusco por su misma dinámica y en el actual proceso de globalización, coexisten situaciones de progreso y atraso, que se ven reflejadas, de un lado, en el crecimiento y modernización económica de algunos sectores y ciudades y, de otro lado en el retraso y pobreza de grandes zonas especialmente rurales.

El Modelo Conceptual de Desarrollo ${ }^{4}$ del Plan de Desarrollo Regional Concertado Cusco a 2021, con Prospectiva a 2030; se estructura en seis (06) componentes que representan las temáticas principales del territorio:

1. Derechos Humanos e Inclusión Social

2. Oportunidad y Acceso a los Servicios

3. Estado y Gobernabilidad

4. Desarrollo Económico Sostenible

5. Cohesión Territorial e Infraestructura Productiva

\section{Gestión del Ambiente}

Los cuales están alineados al Plan Estratégico de Desarrollo Nacional (PEDN), con sus respectivos Sub Componentes condicionados por las características particulares que posee nuestro territorio.

El progreso y avance del Cusco nos demanda retos que aún son formidables. Comprobamos hoy una condición que nos aqueja: el presente está cambiando vertiginosamente ya que todo el mundo:

- Se mueve bajo una sola economía integrada (producción, comercio, flujos financieros, difusión tecnológica, entre otros),

4 El Modelo Conceptual De Desarrollo, se define como la representación de una estructura sistémica, que permita la comprensión del territorio como el espacio geográfico delimitado por un conjunto de sistemas socioeconómicos, ambientales, políticos, culturales e institucionales analizados por medio de componentes y sub componentes identificados. 
- Acelera un poco más la velocidad (gracias al impacto de las nuevas tecnologías de la información y comunicación),

- Se ha convertido en una vasta red sociocultural por la que circula todo el conocimiento.

Es obvio que en la ciudad del Cusco y en la Región del Cusco se han hecho esfuerzos por hacer notar su voz en la dinámica nacional, pero ¿es esto suficiente para cumplir con su compromiso histórico dentro de la dinámica actual en la que está inmersa?

En vez de honrar la obligación sagrada de vivir con intensidad nuestro presente, se da una importancia superlativa al pasado. Estamos aquí para levantar a nuestra Región del Cusco, que espera ansiosa a que sus habitantes la honren por medio de su acción y voluntad. Recordemos que esté presente no lo viviremos dos veces, y de nosotros depende que en algún momento de nuestra historia se diga que fuimos útiles, que enfrentamos dificultades, que nos ganamos el respeto del mundo y que fuimos quienes nos atrevimos a exportar este espíritu. Esto es lo que olvidamos y es lo que hoy recordamos. Se hace necesaria una colaboración más efectiva entre las instituciones públicas y privadas, así como en los diferentes sectores y actores sociales, teniendo como base todo lo actualmente trabajado.

Estamos en el tiempo del ñoqanchis y del ruway, entendiendo este vocablo en su real dimensión de hacer, pero hacer bien con voluntad, diligencia y en armonía.

Tenemos el privilegio de compartir nuestra existencia con esta leyenda viva: ¡el Cusco eterno! fundamento de nuestra Región Cusco. Hagamos nuestra parte, sonriamos a la vida y escribamos con sabiduría la historia actual, construyamos un presente digno de recordar, en unidad, dentro de nuestra diversidad. No se trata de buscar cómo adaptarse a la globalización, sino se trata de ver cómo construir alternativas de alcance local, regional, nacional y mundial, en el marco actual. Para tal efecto considero que es necesario:

1. Precisar qué paradigma y/o modelo de desarrollo se va a impulsar de acuerdo a los tiempos y las realidades regionales actuales para el crecimiento y desarrollo sostenible de la Región Cusco, en un mundo globalizado. Por lo que se hace necesario determinar los roles estratégicos del sector público y privado, definir además la manera de financiar el desarrollo regional del Cusco y cuáles serán los actores que tomen el liderazgo y cumplan estos objetivos.

2. La planificación y desarrollo del territorio: se debe desarrollar una visión, misión y valores; previa la realización de un estudio axiológico del Cusco y los cusqueños, y responsabilizar al cusqueño por su presente y su futuro. Teniendo como eje la internalización y proyección histórica del Cusco y el Perú en el escenario mundial.

3. Visionar que el Cusco debe desarrollar industrias y contar como mínimo con una planta petroquímica, gracias a las potencialidades con que cuenta (especialmente minero-energéticas), y las singularidades que genera en el escenario local, nacional y mundial.

4. Definir el rol del turismo en función a su importancia actual; ya que ahora se ejerce a escala limitada, por lo tanto, es un sector con techo de crecimiento, hay deficiencias de infraestructura turística: hoteles, restaurant es, aero puerto, carreteras, puentes en mal estado y saturad os, terminales terrestres inadecuados, etc. Hay una gestión pública de los monumentos ajena al mercado: que no contempla accesos, calidad de la visita, calidad de atención entre otros. Tengamos presente que el aeropuerto de Chinchero, implica el arribo de 4’000,000 de turistas al año 
como mínimo y pensemos las repercusiones de todo lo que esto significa.

5. Para que este crecimiento económico que ha tenido el Cusco sea beneficioso para todos los cusqueños necesitamos que ese mismo crecimiento se dé en la economía de cada uno de los ciudadanos del Cusco. Por ello debemos promover que el sector público y privado trabajen armoniosamente y que el empresariado cusqueño desde el micro, hasta el gran empresario, generen cadenas productivas (clústeres) en convenio con la Cámara de Comercio y las Gerencias de Desarrollo Económico de los Gobiernos Locales y

del Gobierno Regional del Cusco.

6. La ejecución del ansiado túnel de la Verónica que cruza el abra de Málaga y da acceso a la provincia de La Convención, y así articular e integrar esta zona de valioso potencial económico.

7. La implementación del metro del Cusco, transporte que podría llevarse a cabo haciendo uso de la vía ferroviaria con trenes de alta velocidad y uso exclusivo
8. Superar nuestro desfase científico y tecnológico; el atraso no se puede convertir en patrimonio cultural (eso sería muy dañino).

9. Todas las instancias del Gobierno deben estar en permanente coordinación y articulación.

Por lo dicho, sólo me queda expresar lo que nuestro inmortal bardo César Vallejo escribiera sobrecogido por su entrañable amor a su patria y la humanidad: "... hay, hermanos, muchísimo que hacer" (Vallejo, 1959, pág. 40); por lo que es necesario unir voluntades y actuar para honrar nuestro presente.

\section{REFERENCIAS}

BCRP. (22 de Julio de 2016). Banco Central de Reserva del Perú. Obtenido de Banco Central de Reserva del Perú Sucursal Cusco: http://www.bcrp.gob.pe/docs/ Sucursales/Cusco/cusco-caracterizacion.pdf

D’Medina Lora, E. (2012). El modelo económico peruano: más allá de la leyenda. (S. d. UPC, Ed.) Revista de Economía y Derecho, 9(36), 53-54.

Daniels, J., Radebaugh, L., \& Sullivan, D. (2012). Negocios Internacionales: ambientes y operaciones (Vol. Prentice Hall). México: Pearson Educación.

Gobierno Regional Cusco. (2013). Plan Estratégico 
desde Urcos, provincia de Quispicanchis, hasta Poroy en la provincia del Cusco, zonas periféricas que prácticamente hoy se encuentran totalmente integradas a la vida urbana del Cusco; con alimentadores transversales (funiculares y buses) que aportarían los pasajeros a la línea férrea principal.
Institucional 2012-2016. Cusco, Perú: Gobierno Regional Cusco.

Gobierno Regional del Cusco - CEPLAN. (2016). Plan de Desarrollo Regional Concertado Cusco al 2021, con Prospectiva al 2030 . Cusco: Gobierno Regional Cusco.

Gutiérrez Samanez, J. A. (13 de abril de 2008). cusquenosilustres.blogspot.pe/2008/04/humberto-vidal-unda-cre ador-de-la.html. Obtenido de cusquenos-ilustres. blogspot.pe: http://cusquenos-ilustres.blogspot. pe/2008/04/humberto-vidal-unda-creador-de-la.html

Vallejo, C. (1959). Poemas Humanos: los nueve monstruos. Lima, Lima, Perú: Editora Perú Nuevo. 